\title{
Circumferential management of unstable thoracolumbar fractures using an anterior expandable cage, as an alternative to an iliac crest graft, combined with a posterior screw fixation: results of a series of 85 patients
}

\author{
Thomas Graillon, M.D., ${ }^{1,2}$ Patrick Rakotozanany, M.D., ${ }^{1,2}$ Benjamin Blondel, M.D., ${ }^{1,3}$ \\ Tarek Adetchessi, M.D., ${ }^{1,2}$ Henry Dufour, M.D., ${ }^{1,2}$ And Stéphane Fuentes, M.D., ${ }^{1,2}$ \\ ${ }^{1}$ Department of Spine Surgery, Aix-Marseille University; ${ }^{2}$ APHM, Service Neurochirurgie, Hôpital de la \\ Timone; and ${ }^{3}$ APHM, Service Orthopédie, Hôpital Nord, Marseille, France
}

\begin{abstract}
Object. The optimal management of unstable thoracolumbar fractures remains unclear. The objective of the present study was to evaluate the results of using an expandable prosthetic vertebral body cage (EPVBC) in the management of unstable thoracolumbar fractures.

Methods. Eighty-five patients with unstable T7-L4 thoracolumbar fractures underwent implantation of an EPVBC via an anterior approach combined with posterior fixation. Long-term functional outcomes, including visual analog scale and Oswestry disability index scores, were evaluated.

Results. In a mean follow-up period of 16 months, anterior fixation led to a significant increase in vertebral body height, with an average gain of $19 \%$. However, the vertebral regional kyphosis angle was not significantly increased by anterior fixation alone. No significant difference was found between early postoperative, 3-month, and 1-year postoperative regional kyphosis angle and vertebral body height. Postoperative impaction of the prosthetic cage in adjacent endplates was observed in $35 \%$ of the cases, without worsening at last follow-up. Complete fusion was observed at 1 year postoperatively and no cases of infections or revisions were observed in relation to the anterior approach.

Conclusions. The use of EPVBCs for unstable thoracolumbar fractures is safe and effective in providing longterm vertebral body height restoration and kyphosis correction, with a moderate surgical and sepsis risk. Anterior cage implantation is an alternative to iliac bone graft fusion and is a viable option in association with a posterior approach, in a single operation without additional risks. (http://thejns.org/doi/abs/10.3171/2014.5.FOCUS1452)
\end{abstract}

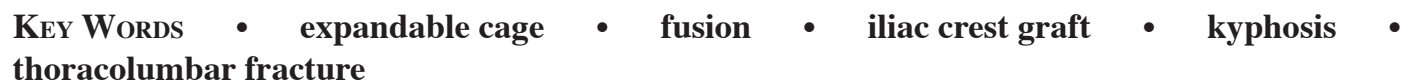

$\mathrm{T}$ HORACOlumbar fractures are common and can be responsible for neurological compromise and early or delayed posttraumatic kyphotic deformity. Correction and prevention of the kyphotic deformity represent a surgical challenge; presence of a kyphotic deformity has been related to worse clinical outcomes than the absence of such a deformity. ${ }^{15,30,40}$ Management of unstable thoracolumbar fractures remains a matter of debate in terms of the optimal surgical strategy. Proposed strategies include conservative treatment, a conventional posterior procedure, percutaneous posterior fixation, and anterior approaches (with placement of an iliac bone graft or prosthetic cage). ${ }^{5,12,16,24,31,35,39}$ Given this absence of a therapeutic consensus, surgical indications and procedures vary with surgical teams and experience.

Various studies have demonstrated the use of an anterior approach to correct posttraumatic kyphosis and

Abbreviation used in this paper: VAS = visual analog scale. stabilize thoracolumbar fractures. ${ }^{2,27,28,34,37}$ However, the ability of anterior arthrodesis to prevent delayed kyphosis remains is a matter of debate, even though the procedure can be required for Magerl Type A.3.2 and A.3.3 burst fractures or for intervertebral disc lesions.

Among the various anterior techniques, an iliac bone graft is commonly used to promote a solid intervertebral fusion. ${ }^{4,6}$ However, recent technical advances and complications associated with graft material have led to the development of titanium vertebral body cages as alternatives to iliac bone grafting.

The objective of this study was to evaluate the use of expandable titanium vertebral body cages for the management of thoracolumbar unstable spine fractures.

\section{Methods}

Study Design and Patient Population

A total of 85 patients were included in this retrospec- 


\section{T. Graillon et al.}

tive study, which was approved by the ethics committee of the Aix-Marseille University and undertaken after informed consent was obtained from each patient. Patients were admitted for the management of an unstable thoracolumbar fracture. Inclusion criteria required the presence of a burst fracture or unstable vertebral fracture that would require an anterior arthrodesis according to the Load Sharing Classification described by McCormack et al. ${ }^{21}$ The presence of initial neurological deficit was not an exclusion criterion. A modified Frankel scale grade was determined (American Spinal Injury Association/International Medical Society of Paraplegia. International standards for neurological and functional classification of spinal cord injury patients [revised]. Chicago, IL: American Spinal Injury Association, 1992). Patients with a medical history of metastatic or evolving cancer, severe osteoporosis, or inflammatory and active infectious disease were excluded from the study. Severe osteoporosis was defined as 2 or more osteoporotic fractures and confirmed on osteodensitometry.

Initial CT scanning was performed systematically to classify the fracture, to determine the need for an anterior intervertebral graft, and to establish radiographic measurements.

Patients were evaluated early after surgery, at 3 months, at 1 year, and then annually thereafter. Postoperative radiographic evaluation included CT scans in all the cases, to measure the restored vertebral body height and regional and vertebral kyphosis. At 3 months, 79 patients were evaluated. At 1 year, 50 patients were evaluated.

Pain was evaluated using a visual analog scale (VAS) in the preoperative period, on the day of discharge, at 3 months (79 patients), and at 1 year (50 patients) after surgery. Functional outcome was evaluated using the Oswestry Disability Index ${ }^{17}$ at 1 year postoperatively in the 50 patients available at that follow-up time. Disability was considered minimal when between $0 \%-30 \%$, moderate between $31 \%-50 \%$, and severe between $51 \%-100 \%$.

\section{Fracture Classification}

Thoracolumbar fractures were classified according to the Magerl Classification and Load Sharing Classification $^{20}$ : 75 fractures were classified as Type A.3.3, 3 as Type A.3.2, and 7 as Type C. The Magerl classification grade was determined using axial, coronal, and sagittal CT scans, which also allowed for measurement of vertebral height and the regional and vertebral kyphosis angle. According to the Load Sharing Classification, patient scores averaged 8.1 (range 7-9).

Vertebral height was defined as the ratio between the height of the anterior wall of the fractured vertebral body and the height of the anterior wall of the inferior adjacent body. Vertebral regional kyphosis was defined as the angle between the superior endplate of the adjacent superior vertebra and the inferior endplate of the inferior adjacent vertebra. Vertebral kyphosis was defined as the angle between the superior and inferior endplates of the fractured vertebral body. Postoperative vertebral height and the regional and vertebral angle were systematically compared with findings on preoperative CT scans.

\section{Surgical Indication}

In cases of unstable thoracolumbar fractures (Magerl Type A.3.2, A.3.3, and C fractures), because surgery was indicated, we used a posterior approach except in cases of thoracic fractures with an intact posterior wall. Shortsegment fixation (1 level above and 1 level below) procedure was classically performed except in cases involving Magerl Type C fractures, severe kyphotic deformity, or significant vertebral height loss that required fixation encompassing the 2 levels above and 2 levels below the fracture. Conventional posterior approaches were used in all the cases with neurological deficit, and a percutaneous procedure was used in all the other cases. A second procedure, anterior fixation, was proposed in cases of previous significant vertebral height loss ( $>40 \%)$, previous severe kyphotic deformity, an MRI-documented intervertebral disc lesion, and cortical bone intervertebral disc herniation. Postoperative CT scanning helped in deciding on whether anterior fixation should also be performed. A combined posterior-anterior approach was chosen in cases of pseudarthrosis, severe vertebral height loss, or kyphotic deformity requiring anterior fixation.

\section{Surgical Technique}

Kyphosis correction was systematically performed. Posterior approaches were used to stabilize and reduce kyphotic deformity.

The anterior approach technique was adapted to the respective level of the fractured vertebra: 1) A mini-thoracotomy (4-cm skin incision) was performed for T7-8 fractures, using a right lateral approach under fluoroscopic guidance and selective intubation for pulmonary retraction. A partial rib resection was performed via a subperiosteal pathway, enabling a parietal pleural layer exposure. After incision of the parietal layer, a trans- or retropleural approach was performed. 2) For fractures between T-9 and L-1, a transthoracic approach was combined with a subcostal retroperitoneal procedure, using a left lateral approach through a 5-cm skin incision. 3) For fractures between L-2 and L-4, a left subcostal retroperitoneal approach was used. Muscle dissection and incision provided access to the retroperitoneum. 4) In all cases, the fractured vertebral body was located using fluoroscopy. A partial corpectomy was performed and then completed by resection of the superior and inferior discs. The goal of the surgery was not to completely decompress the canal but only to create space for the cage, except in cases of persistent anterior spinal cord compression. An expandable vertebral body cage (V-lift, Stryker; or TeCorp, Scient'x), filled with cancellous bone obtained from the corpectomy site and the rib, was then centrally positioned before distraction. Additional anterior fixation, if needed, was performed using a screw/plate system (Vantage, Medtronic; or Lyra, Scient'x). Intraoperative blood loss and operating time were quantified.

\section{Fusion Criteria}

Fusion criteria, based on CT scans and spine radiographs, were as follows: the absence of hypodensity around pedicular screws, absence of or minimal presence 
of vertebral height loss, absence of significant cage impaction, absence of hardware failure, absence of vertebral plate hyperdensity, and presence of trabecular bone bridge formation around and inside the intervertebral cage.

The fusion was considered complete when all these criteria were observed. When intervertebral body bone bridges were not completely fused, especially around the cage, we concluded that fusion was incomplete. ${ }^{3,18,32}$ Control CT scans were reviewed and analyzed by a specialist radiologist not involved in the patient treatment.

\section{Statistical Analysis}

Statistical analysis was performed using a Wilcoxon t-test. The level of significance for all the statistical analyses was set at $5 \%$.

\section{Results}

\section{Patient Population}

A total of 85 patients were included in this retrospective study and were treated by a single spine surgeon for thoracolumbar fractures from T-7 to L-4 (Fig. 1). Posterior and anterior approaches were used. Overall, there were 41 females and 44 males whose mean age was 41 years (range 16-74 years). The mean follow-up duration was 16 months (range 6-36 months). Six patients were lost to (3-month) follow-up and 50 patients were available for 1-year follow-up.

The total mean delay between the posterior and anterior approach was 7 days. The mean delay was 11 days (range 2-45 days) when an anterior approach was determined to be needed following posterior surgery. The mean delay was 161 days (range 45-330 days) when pseudarthrosis was seen following posterior fixation. Overall, 18 patients had pseudarthrosis, including 4 patients who had previously undergone surgery via a posterior approach. Posterior and anterior approaches were performed in the same session in 12 cases.

Preoperative neurological evaluation using the Frankel classification revealed Grade E status in 74 patients, Grade A in 9, and Grade C in 2.

\section{Vertebral Height Loss Correction}

Anterior fixation using expandable titanium cages significantly enhanced vertebral height loss relative to that seen on preoperative CT scan, with an average gain of $+19 \%$ in the 85 patients $(\mathrm{p}=0.0001)$. The mean CTdocumented vertebral height loss was $-46 \%$ on the preoperative scan, $-27 \%$ after posterior fixation, and $-14 \%$ after anterior cage placement (Fig. 2). Therefore, anterior fixation provided a $+13 \%$ increase in vertebral body height $(\mathrm{p}=0.0001)$. In each case, expansion of the cage was performed (Fig. 3). During follow-up evaluation (3 months $[\mathrm{n}=79]$ and 1 year $[\mathrm{n}=50])$, the mean vertebral height loss was $-14 \%$ and $-13 \%$, respectively. No significant difference $(\mathrm{p}=0.6)$ was found when comparing early, 3-month, and 1-year postoperative vertebral height loss (Fig. 4).

\section{Correction of the Kyphotic Deformity}

Mean corrections of the vertebral regional kyphosis angle and vertebral kyphosis seen immediately postoperatively in the 85 patients were $-1^{\circ}$ and $-2^{\circ}$, respectively ( $\mathrm{p}$ $=0.08$ ). Therefore, vertebral regional kyphosis angle and vertebral kyphosis were not significantly reduced by the anterior fixation and cage expansion (Fig. 3). The main kyphosis correction was the result of posterior distraction, with an average reduction of $-7^{\circ}$. No significant difference was found when comparing early, 3-month, and 1-year postoperative vertebral regional kyphosis angle ( $\mathrm{p}$ $=0.3$ ) (Fig. 4).

\section{Vertebral Prosthetic Cage Subsidence}

Postoperative subsidence of the prosthetic cage in the superior or inferior vertebral endplate was observed in $35 \%$ of the cases. This subsidence was millimetric $(2-7 \mathrm{~mm})$ and was not correlated with postoperative pain. No subsidence worsening was observed during the follow-up of the 79 patients at 3 months and the 50 patients at 1 year.

\section{Surgical Data}

The mean operating time for an anterior approach was 69 minutes, with an average of 60 minutes for a subcostal retroperitoneal approach and 80 minutes for a thoracotomy. The mean operating time for a combined posterior-anterior approach was 185 minutes.

Average blood loss related to the anterior approach was $250 \mathrm{ml}$, and no perioperative blood transfusion was required.

\section{Postoperative Complications}

Postoperative pleural fluid collections were observed

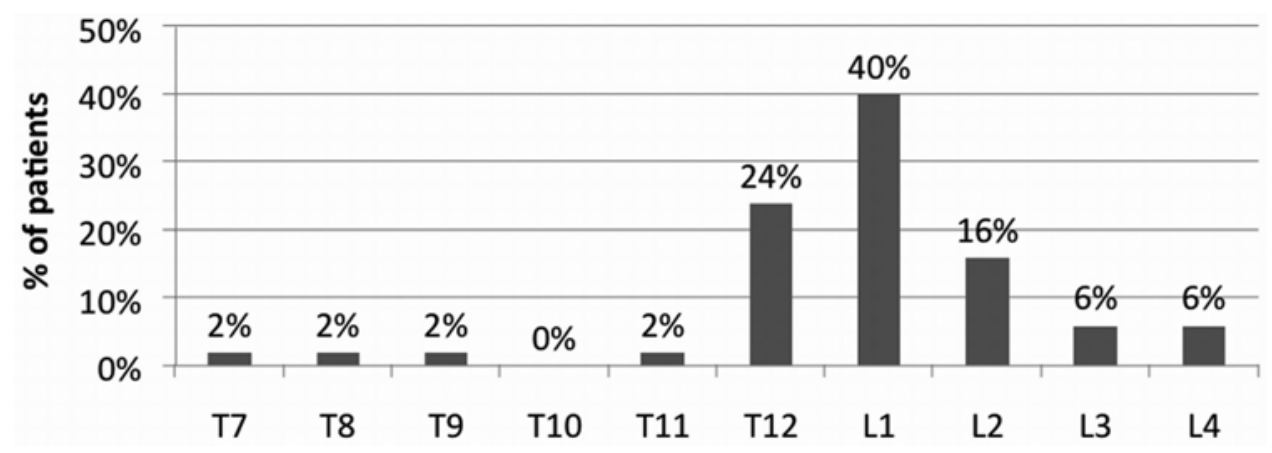

FIG. 1. Graph showing the incidence of fractures stratified by affected vertebra. 


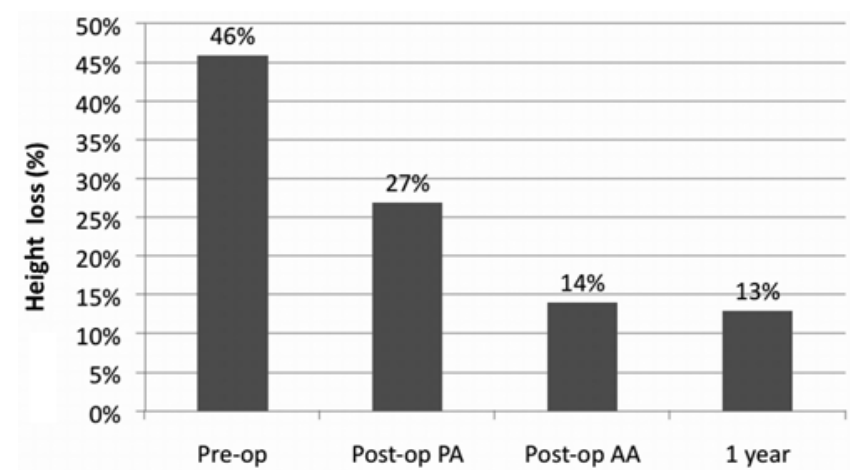

Fig. 2. Graph demonstrating the mean vertebral height loss in the preoperative period (Pre-op), in the postoperative period after the posterior approach (Post-op PA), and after the anterior approach (Post-op $A A)$, and at long term (1 year).

in 4 cases, with only 1 case that required chest tube drainage for a recurrence 5 days after surgery. No severe complications were observed following the subcostal retroperitoneal approach.

On the whole, no infections were found after the anterior approach, and no anterior revision surgery was required. Three patients had a posterior infection, with favorable outcomes after surgical revision and long-term adapted antibiotic therapy. Six postoperative urinary tract infections were diagnosed. In each case, patients were suffering from neurological sphincter deficit and underwent bladder drainage.

Three cases of postoperative neuropathic pain were observed, with eventual favorable outcomes.

\section{Fusion Status}

Complete fusion was observed between 3 months and 1 year after surgery. At 3 months, incomplete fusion was observed in each case (79 cases): bone fusion inside the cage and intervertebral bone bridge formation around the cage. Complete fusion was systematically observed at 1
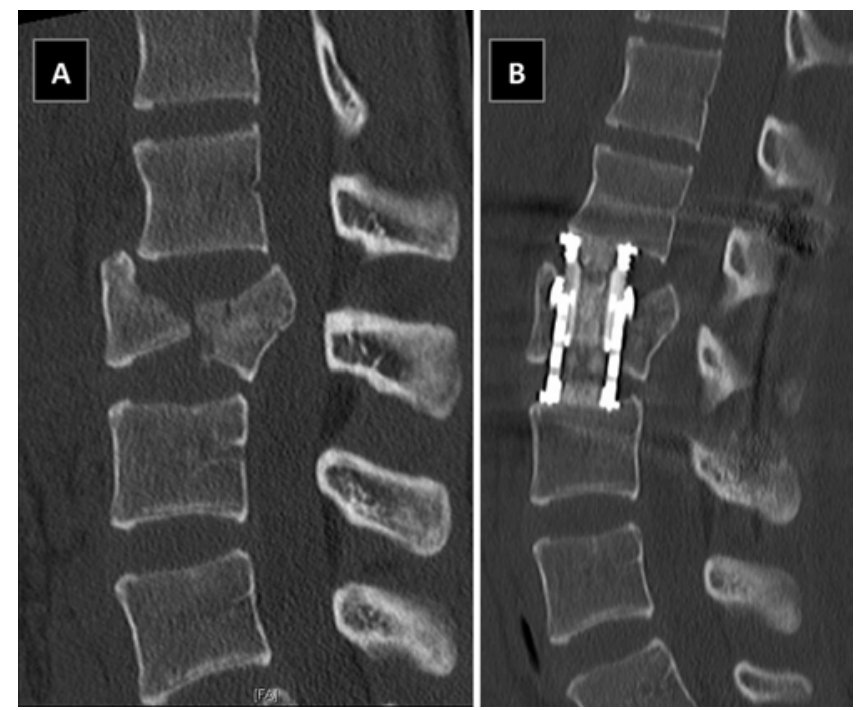

FIG. 3. Kyphotic deformity correction. Preoperative (A) and postoperative (B) CT scans showing kyphosis deformity correction and vertebral height loss reduction after anterior and posterior fixation. year without any case of hardware failure or rod fracture (50 of 50 cases). Subsidence, when documented on the postoperative CT scan, remained stable without delayed migration of the cage. No surgical revision was required after anterior fixation.

\section{Functional Outcome}

Back pain was evaluated using a 10-point VAS. In 50 patients for whom 1-year follow-up data were available, the mean VAS back pain score was 8 before surgery, 6 on the day of discharge from the hospital, 4 at 3 months after surgery, and 3 at 1 year after surgery. At 1 year postoperatively, in the same 50 patients, $29 \%$ had no pain, $57 \%$ intermittent pain, and $14 \%$ permanent pain, respectively (Fig. 5).

The Oswestry Disability Index was used to evaluate 50 patients at 1 year after surgery; $54 \%$ had minimal disability, 39\% had moderate disability, and $7 \%$ had severe disability (Fig. 6). Of the patients with a job, $72 \%$ returned to work at an average of 6 months after surgery (range 3 weeks to 2 years).

\section{Discussion}

\section{Surgical Strategy}

Despite numerous published reports, the optimal management of unstable thoracolumbar vertebral fractures remains without strong therapeutic consensus. Conservative therapies using braces have been advocated for burst fractures in patients without neurological symptoms and with moderate kyphosis deformity $(<40 \%$ of vertebral height loss and $<50 \%$ of spinal canal stenosis). ${ }^{12,24,30,35,39}$ However, as observed in some patients in our series, the possibility of a delayed kyphotic deformity underlines the risk associated with insufficient fixation and stabilization of thoracolumbar fractures. The aim of surgical management of these vertebral lesions is to decompress neural structures, to stabilize spinal instability, and to correct the posttraumatic kyphotic deformity. Numerous techniques have been described to date, but choosing the best one remains complicated and the choice depends on various factors related to the fracture, the patient, and the surgical team's experience. Currently, no significant correlation between kyphosis correction and clinical outcomes has been demonstrated, perhaps due to the difficulty of determining the optimal outcomes criteria. ${ }^{15,30,40}$ As an example, the major factors for return to work are associated with education level and absence of compensatory complaints. ${ }^{5,31,36}$

Like many authors, we contend that surgical management of unstable spinal fractures can provide satisfactory results, but questions remain as to how best to treat these lesions. Performing short-segment posterior fixation with pedicle screws can allow lordotic distraction for restoration of vertebral body height and kyphosis correction. ${ }^{1,16,23,31}$ A posterior approach can also achieve good decompression when required.

However, many studies have reported as much as $7^{\circ}-$ $16^{\circ}$ kyphosis reduction loss during the 1st postoperative year, mainly owing to lesions of the superior intervertebral disc and the superior endplate of the fractured vertebra. 1,16,19,23,25,31,39 To prevent this loss of correction, pos- 


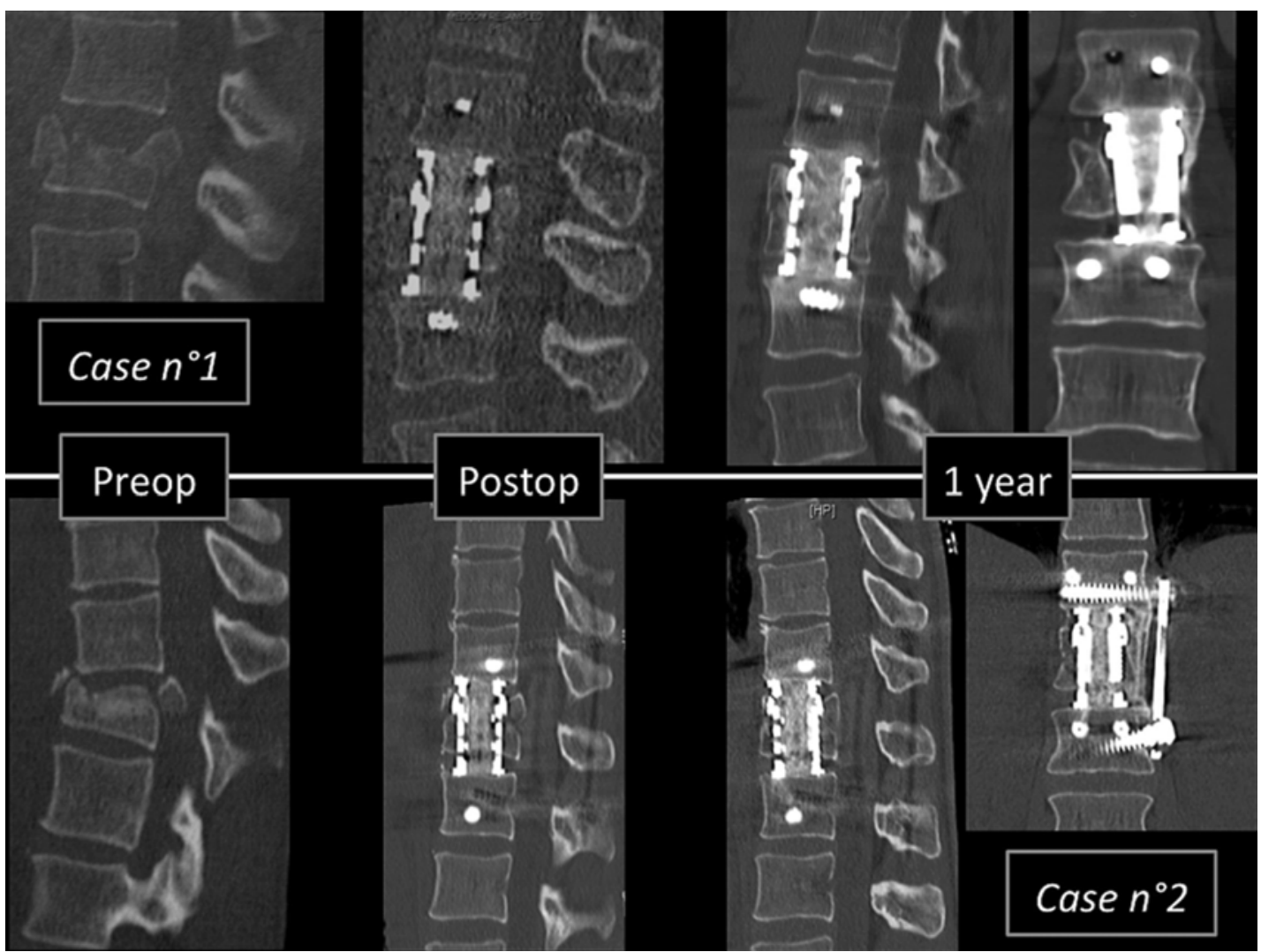

FIG. 4. Delayed kyphotic deformity correction and vertebral height loss reduction at 1 year. Preoperative and postoperative CT scans of 2 representative cases of thoracolumbar unstable fractures. Kyphotic deformity correction and vertebral height loss reduction are stable at 1 year. Fusion is observed at 1 year on coronal sequences.

terior fusion has been recommended, but posterior bone grafts have also been reported to be unable to prevent delayed postoperative kyphotic deformity.1,16,23,31 In 4 cases in the present series, a delayed postoperative kyphotic deformity required complementary anterior fixation with a vertebral prosthetic cage implantation, underscoring the potential interest of early anterior fixation.
Anterior Approach: Long-Term Stable Kyphosis Correction With Limited Adverse Effects

Some authors have proposed anterior approach surgery as the first and even only procedure. The main drawback with this strategy is that during the first few days following the fracture the intraoperative hemorrhagic risk

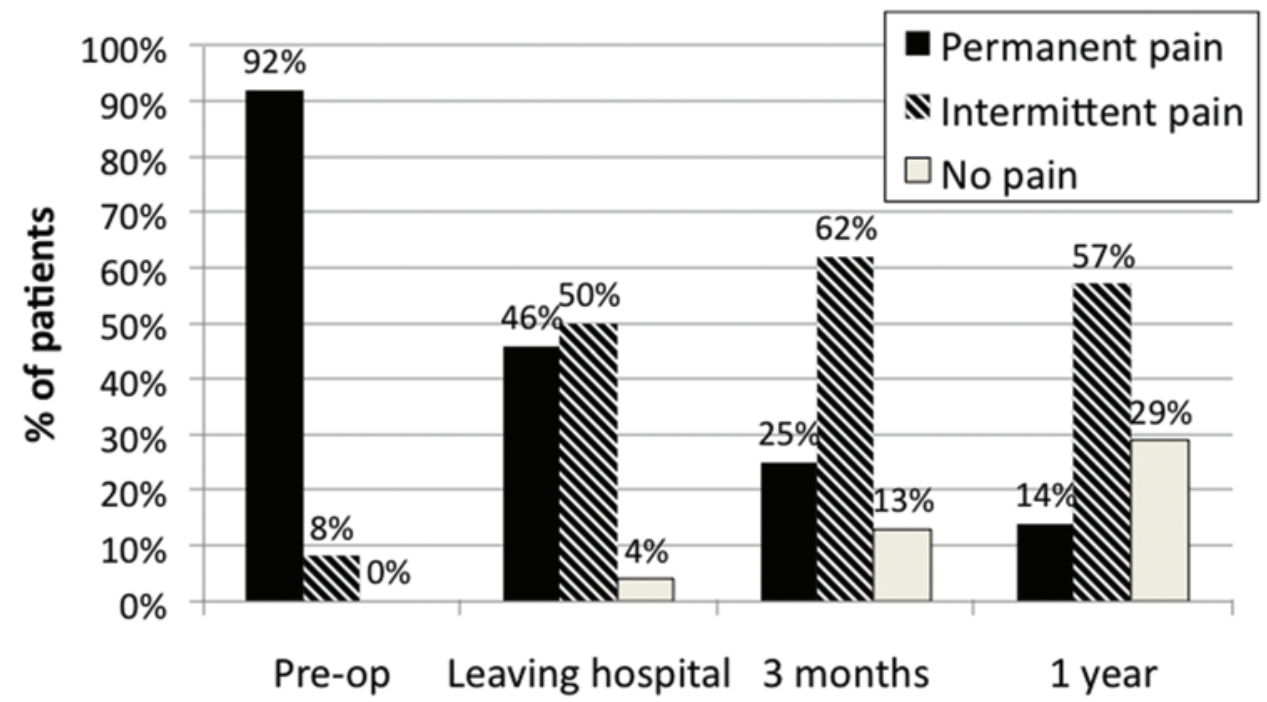

FIG. 5. Postoperative back pain study. Back pain intensity was quantified using a VAS in 50 patients during the posttraumatic preoperative period, when leaving the hospital, at 3 months after surgery, and at 1 year after surgery. 


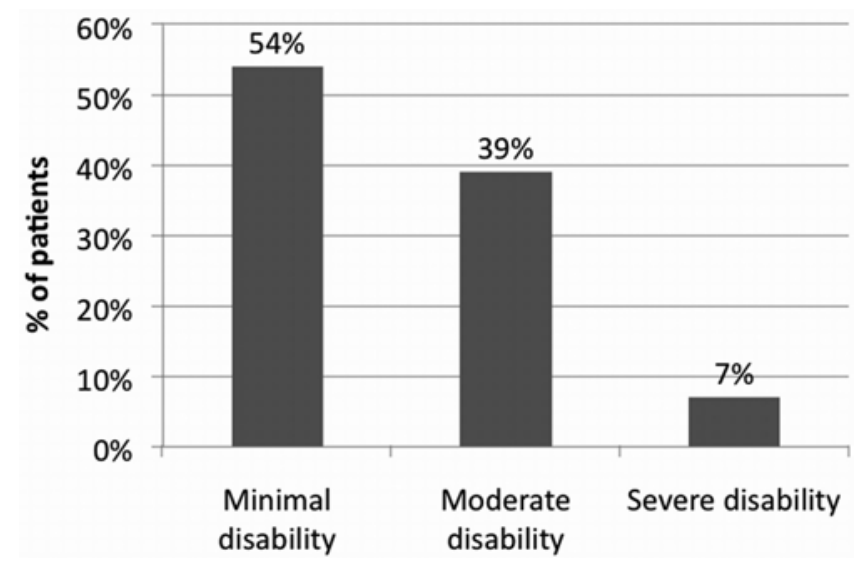

FIG. 6. Long-term disability was evaluated using the Oswestry Disability Index 1 year after surgery in 50 patients (0\%-30\%: minimal disability; 31\%-50\%: moderate disability; and 51\%-100\%: severe disability).

is higher, potentially requiring blood transfusion and extending surgical time and posing difficulties.,22,29 Similarly, blood loss appears to be significantly higher during anterior surgery than posterior surgery in the first few posttraumatic days..$^{5,19,22,29,41}$ Moreover, anterior fixation provides less kyphosis correction than posterior fixation, even if it leads to better long-term kyphosis correction outcomes. ${ }^{5,8,11,14,26,41}$

Performing a combined approach can therefore be a good option, and mechanical studies have highlighted the association of the combined approach with good spinal stability. ${ }^{28,34}$ Thus, combining the anterior approach and posterior approach ${ }^{2}$ and using expandable cages could be an alternative strategy to enhance vertebral deformity correction when compared with option involving nonexpandable cages. Results from the literature show a moderately better distraction force associated with expandable cages compared to nonexpandable cages ${ }^{7}$ and similar biomechanical properties. ${ }^{28}$

Comparing the combined approach with an isolated posterior approach, Verlaan et al. ${ }^{37}$ observed a mean $10^{\circ}$ kyphosis reduction loss during the first postoperative year following a posterior approach alone. Combining a posterior approach with anterior implantation of a titanium cage, Payer et al. observed a mean $3^{\circ}$ kyphosis reduction loss during the first 2 postoperative years. ${ }^{27}$ Biomechanical studies have shown that titanium vertebral cages are resistant to axial compression..$^{28}$ Our findings are in agreement with these findings; we observed no significant kyphosis correction loss at the last follow-up and complete fusion was documented in 50 of 50 patients 12 months after surgery.

To avoid a second anterior approach procedure, some authors have described a corpectomy and vertebral prosthetic cage implantation via a posterior approach alone., $, 13,33$ However, despite the interest of this theoretically, in practice cage implantation via a posterior approach remains questionable in terms of the risk of spinal cord injury during implantation. One should also consider the increased risk of severe bleeding and sepsis-related complications associated with a longer operating time. , 13,33 $^{2}$
In our study, adverse effects of the anterior approach were moderate ${ }^{10,38}$ (no case of cage infection and no surgical revision after the anterior approach), and classic adverse effects after thoracotomy and subcostal retroperitoneal approach were acceptable. ${ }^{27}$

\section{Prosthetic Vertebral Cage or Iliac Bone Graft}

One advantage of titanium prosthetic vertebral cages is that one can avoid harvesting of iliac crest bone and thus donor-site complications such as infection, hematoma, iliac crest fracture, and delayed neuropathic pain with postoperative meralgia. Also, the biomechanical properties of the cages are similar to those of iliac bone graft: no difference has been demonstrated in terms of stability and fusion status rate. ${ }^{4,6}$ Vertebral cages could be considered as a structural support for bone graft.

\section{Combined Posterior and Anterior Approach}

The limited adverse effects of the anterior approach and vertebral cage implantation, with moderate blood loss and favorable long-term outcomes, led us to consider a single operation that combines percutaneous posterior fixation and anterior cage placement. The main objectives are to limit general anesthesia procedures for the patient and accelerate postoperative recuperation, which reduce care costs. In our opinion, vertebral fracture pseudarthrosis appears to be an excellent indication for performing a combined approach in a single procedure because the delay in the traumatic injury limits bleeding risk. However, favorable outcomes and limited complications suggest that the indications could be extended to acute thoracolumbar fractures.

\section{Conclusions}

Expandable titanium vertebral cage implantation in a procedure that combines the posterior and anterior approach to manage unstable thoracolumbar fractures is safe and effective in providing long-term vertebral body height and kyphosis correction; the fusion rate was excellent and risks were moderate. Anterior cage implantation represents an interesting alternative to iliac bone graft fusion and the combined approach can, with experience, even be considered in a single surgical procedure without additive risks.

\section{Disclosure}

Dr. Blondel is a consultant for SpineGuard and Medicrea.

Author contributions to the study and manuscript preparation include the following. Conception and design: Graillon, Fuentes. Acquisition of data: Graillon, Rakotozanany, Adetchessi. Analysis and interpretation of data: Graillon, Fuentes. Drafting the article: Graillon, Fuentes. Critically revising the article: Blondel, Fuentes. Reviewed submitted version of manuscript: Adetchessi, Dufour, Fuentes. Statistical analysis: Graillon. Administrative/technical/ material support: Dufour. Study supervision: Dufour.

\section{References}

1. Alanay A, Acaroğlu E, Yazici M, Aksoy C, Surat A: The effect of transpedicular intracorporeal grafting in the treatment 
of thoracolumbar burst fractures on canal remodeling. Eur Spine J 10:512-516, 2001

2. Been HD, Bouma GJ: Comparison of two types of surgery for thoraco-lumbar burst fractures: combined anterior and posterior stabilisation vs. posterior instrumentation only. Acta Neurochir (Wien) 141:349-357, 1999

3. Burkus JK, Foley K, Haid RW, LeHuec JC: Surgical Interbody Research Group-radiographic assessment of interbody fusion devices: fusion criteria for anterior lumbar interbody surgery. Neurosurg Focus 10(4):E11, 2001

4. Cardenas RJ, Javalkar V, Patil S, Gonzalez-Cruz J, Ogden A, Mukherjee D, et al: Comparison of allograft bone and titanium cages for vertebral body replacement in the thoracolumbar spine: a biomechanical study. Neurosurgery 66 (6 Suppl Operative):314-318, 2010

5. Carl AL, Tranmer BI, Sachs BL: Anterolateral dynamized instrumentation and fusion for unstable thoracolumbar and lumbar burst fractures. Spine (Phila Pa 1976) 22:686-690, 1997

6. Dai LY, Jiang LS, Jiang SD: Anterior-only stabilization using plating with bone structural autograft versus titanium mesh cages for two- or three-column thoracolumbar burst fractures: a prospective randomized study. Spine (Phila Pa 1976) 34:1429-1435, 2009

7. Eleraky MA, Duong HT, Esp E, Kim KD: Expandable versus nonexpandable cages for thoracolumbar burst fracture. World Neurosurg 75:149-154, 2011

8. Ghanayem AJ, Zdeblick TA: Anterior instrumentation in the management of thoracolumbar burst fractures. Clin Orthop Relat Res (335):89-100, 1997

9. Haiyun Y, Rui G, Shucai D, Zhanhua J, Xiaolin Z, Xin L, et al: Three-column reconstruction through single posterior approach for the treatment of unstable thoracolumbar fracture. Spine (Phila Pa 1976) 35:E295-E302, 2010

10. Heary RF, Kheterpal A, Mammis A, Kumar S: Stackable carbon fiber cages for thoracolumbar interbody fusion after corpectomy: long-term outcome analysis. Neurosurgery 68:810 819, 2011

11. Hitchon PW, Torner J, Eichholz KM, Beeler SN: Comparison of anterolateral and posterior approaches in the management of thoracolumbar burst fractures. J Neurosurg Spine 5:117125,2006

12. Hitchon PW, Torner JC, Haddad SF, Follett KA: Management options in thoracolumbar burst fractures. Surg Neurol 49:619-627, 1998

13. Hofstetter CP, Chou D, Newman CB, Aryan HE, Girardi FP, Härtl R: Posterior approach for thoracolumbar corpectomies with expandable cage placement and circumferential arthrodesis: a multicenter case series of 67 patients. Clinical article. J Neurosurg Spine 14:388-397, 2011

14. Kaneda K, Taneichi H, Abumi K, Hashimoto T, Satoh S, Fujiya M: Anterior decompression and stabilization with the Kaneda device for thoracolumbar burst fractures associated with neurological deficits. J Bone Joint Surg Am 79:69-83, 1997

15. Katscher S, Verheyden P, Gonschorek O, Glasmacher S, Josten $C$ : [Thoracolumbar spine fractures after conservative and surgical treatment. Dependence of correction loss on fracture level.] Unfallchirurg 106:20-27, 2003 (Ger)

16. Knop C, Fabian HF, Bastian L, Rosenthal H, Lange U, Zdichavsky M, et al: Fate of the transpedicular intervertebral bone graft after posterior stabilisation of thoracolumbar fractures. Eur Spine J 11:251-257, 2002

17. Little DG, MacDonald D: The use of the percentage change in Oswestry Disability Index score as an outcome measure in lumbar spinal surgery. Spine (Phila Pa 1976) 19:2139-2143, 1994

18. Lonstein JE, Denis F, Perra JH, Pinto MR, Smith MD, Winter RB: Complications associated with pedicle screws. J Bone Joint Surg Am 81:1519-1528, 1999
19. Louis CA, Gauthier VY, Louis RP: Posterior approach with Louis plates for fractures of the thoracolumbar and lumbar spine with and without neurologic deficits. Spine (Phila Pa 1976) 23:2030-2040, 1998

20. Magerl F, Aebi M, Gertzbein SD, Harms J, Nazarian S: A comprehensive classification of thoracic and lumbar injuries. Eur Spine J 3:184-201, 1994

21. McCormack T, Karaikovic E, Gaines RW: The load sharing classification of spine fractures. Spine (Phila Pa 1976) 19: 1741-1744, 1994

22. McDonough PW, Davis R, Tribus C, Zdeblick TA: The management of acute thoracolumbar burst fractures with anterior corpectomy and Z-plate fixation. Spine (Phila Pa 1976) 29:1901-1909, 2004

23. Müller U, Berlemann U, Sledge J, Schwarzenbach O: Treatment of thoracolumbar burst fractures without neurologic deficit by indirect reduction and posterior instrumentation: bisegmental stabilization with monosegmental fusion. Eur Spine J 8:284-289, 1999

24. Mumford J, Weinstein JN, Spratt KF, Goel VK: Thoracolumbar burst fractures. The clinical efficacy and outcome of nonoperative management. Spine (Phila Pa 1976) 18:955-970, 1993

25. Oertel J, Niendorf WR, Darwish N, Schroeder HW, Gaab MR: Limitations of dorsal transpedicular stabilization in unstable fractures of the lower thoracic and lumbar spine: an analysis of 133 patients. Acta Neurochir (Wien) 146:771-777, 2004

26. Okuyama K, Abe E, Chiba M, Ishikawa N, Sato K: Outcome of anterior decompression and stabilization for thoracolumbar unstable burst fractures in the absence of neurologic deficits. Spine (Phila Pa 1976) 21:620-625, 1996

27. Payer M: Unstable burst fractures of the thoraco-lumbar junction: treatment by posterior bisegmental correction/fixation and staged anterior corpectomy and titanium cage implantation. Acta Neurochir (Wien) 148:299-306, 2006

28. Pflugmacher R, Schleicher P, Schaefer J, Scholz M, Ludwig K, Khodadadyan-Klostermann C, et al: Biomechanical comparison of expandable cages for vertebral body replacement in the thoracolumbar spine. Spine (Phila Pa 1976) 29:1413-1419, 2004

29. Ragel BT, Kan P, Schmidt MH: Blood transfusions after thoracoscopic anterior thoracolumbar vertebrectomy. Acta Neurochir (Wien) 152:597-603, 2010

30. Reinhold M, Knop C, Lange U, Bastian L, Blauth M: [Nonoperative treatment of thoracolumbar spinal fractures. Longterm clinical results over 16 years.] Unfallchirurg 106:566576, 2003 (Ger)

31. Sanderson PL, Fraser RD, Hall DJ, Cain CM, Osti OL, Potter GR: Short segment fixation of thoracolumbar burst fractures without fusion. Eur Spine J 8:495-500, 1999

32. Santos ER, Goss DG, Morcom RK, Fraser RD: Radiologic assessment of interbody fusion using carbon fiber cages. Spine (Phila Pa 1976) 28:997-1001, 2003

33. Sasani M, Ozer AF: Single-stage posterior corpectomy and expandable cage placement for treatment of thoracic or lumbar burst fractures. Spine (Phila Pa 1976) 34:E33-E40, 2009

34. Schreiber U, Bence T, Grupp T, Steinhauser E, Mückley T, Mittelmeier W, et al: Is a single anterolateral screw-plate fixation sufficient for the treatment of spinal fractures in the thoracolumbar junction? A biomechanical in vitro investigation. Eur Spine J 14:197-204, 2005

35. Shen WJ, Shen YS: Nonsurgical treatment of three-column thoracolumbar junction burst fractures without neurologic deficit. Spine (Phila Pa 1976) 24:412-415, 1999

36. Tasdemiroglu E, Tibbs PA: Long-term follow-up results of thoracolumbar fractures after posterior instrumentation. Spine (Phila Pa 1976) 20:1704-1708, 1995

37. Verlaan JJ, Diekerhof CH, Buskens E, van der Tweel I, Verbout AJ, Dhert WJ, et al: Surgical treatment of traumatic frac- 


\section{T. Graillon et al.}

tures of the thoracic and lumbar spine: a systematic review of the literature on techniques, complications, and outcome. Spine (Phila Pa 1976) 29:803-814, 2004

38. Wiggins GC, Rauzzino MJ, Shaffrey CI, Nockels RP, Whitehill R, Alden TD, et al: A new technique for the surgical management of unstable thoracolumbar burst fractures: a modification of the anterior approach and an outcome comparison to traditional methods. Neurosurg Focus 7(1):e3, 1999

39. Wood K, Buttermann G, Mehbod A, Garvey T, Jhanjee R, Sechriest V: Operative compared with nonoperative treatment of a thoracolumbar burst fracture without neurological deficit. A prospective, randomized study. J Bone Joint Surg Am 85-A:773-781, 2003 (Erratum in J Bone Joint Surg Am 86A:1283, 2004)

40. Wood KB, Geissele AE, Ogilvie JW: Pelvic fractures after long lumbosacral spine fusions. Spine (Phila Pa 1976) 21: 1357-1362, 1996

41. Zahra B, Jodoin A, Maurais G, Parent S, Mac-Thiong JM Treatment of thoracolumbar burst fractures by means of anterior fusion and cage. J Spinal Disord Tech 25:30-37, 2012

Manuscript submitted February 9, 2014.

Accepted May 6, 2014.

Please include this information when citing this paper: DOI: 10.3171/2014.5.FOCUS1452.

Address correspondence to: Thomas Graillon, M.D., Service de Neurochirurgie, Hôpital de la Timone Adulte, Rue Saint Pierre, 13385 Marseille Cedex 5, France. email: thomas.graillon@ap-hm. fr. 